\title{
Breast cancer in dense breasts: comparative diagnostic merits of contrast-enhanced mammography and diffusion-weighted breast MRI
}

Reham Anwar ${ }^{1 *}$, Mohamed Amr Farouk², Wafaa Raafat Abdel Hamid ${ }^{3}$, Amal Amin Abu El Maati ${ }^{3}$ and Hanan Eissa ${ }^{3}$

\begin{abstract}
Background: The study was done to compare the value of contrast-enhanced mammography and diffusionweighted breast MRI in dense breast screening and accurate detection of the breast cancer with correlation of the findings to the histopathological results.

The study included 32 female patients having suspicious breast lesions and underwent digital mammography then scheduled for CESM and MRI DW imaging technique. The imaging findings were correlated to the histopathological findings.
\end{abstract}

Results: The study was conducted on 40 breast lesions in 32 female patients having dense breasts; they were classified by the digital mammography into ACR C (59.4\%) and ACR D (40.6\%). By CESM, there were twenty three lesions (57.5\%) as mass lesions and thirteen lesions (32.5\%) as non-mass lesions. Four lesions (10\%) showed no contrast enhancement. According to the lesion characteristics in diffusion-weighted imaging, the breast lesions were classified into thirty three lesions (82.5\%) with restricted diffusion and seven lesions (17.5\%) with nonrestricted diffusion. The study showed a cutoff ADC value to detect the malignant lesions in the dense breasts $\leq$ $1.1 \times 10^{-3} \mathrm{~s} / \mathrm{mm}^{2}$ at $b$ value of $1000 \mathrm{~s} / \mathrm{mm}^{2}$ with a sensitivity of $96.77 \%$, specificity of $66.67 \%$, PPV of $96.77 \%$, NPV of $55.55 \%$, and an overall total accuracy of $92.5 \%$.

On comparing the diagnostic accuracy of the CESM to that of the DW MRI, the sensitivity of DW MRI (96.77\%) was higher than that of CESM (90.32\%). The specificity of DW MRI (66.67\%) was higher than that of CESM (33.33\%). Total accuracy of DW MRI was higher than that of CESM; they were $90 \%$ and $77.5 \%$, respectively. Also, PPV and NPV of DW MRI were 90.91 and $85.71 \%$ as compared with 82.35 and 50.00\% in CESM, respectively. When comparing the sensitivity of CESM to DW MRI in the detection of multiple breast lesions, they were 88.8 and $100 \%$, respectively.

Conclusion: CESM is a useful technique in identification of hidden lesions in mammographically dense breasts. DW MRI is a fast, unenhanced modality that can be used as a breast cancer screening modality. CESM and DWI demonstrated good overall diagnostic accuracy in dense breast patients; however, DW MRI has a higher diagnostic accuracy than CESM for the detection of malignant breast lesions and their multiplicity.

Keywords: Breast cancer, Dense breasts, Contrast-enhanced spectral mammography (CESM), Diffusion-weighted MRI (DW MRI), Apparent diffusion coefficient (ADC)

\footnotetext{
* Correspondence: drrehamanwar@gmail.com

'Department of Diagnostic Radiology, Dar Elsalam Cancer Center, Ministry of

Health, Cairo, Egypt

Full list of author information is available at the end of the article
}

\section{Springer Open}

(c) The Author(s). 2021 Open Access This article is licensed under a Creative Commons Attribution 4.0 International License, which permits use, sharing, adaptation, distribution and reproduction in any medium or format, as long as you give appropriate credit to the original author(s) and the source, provide a link to the Creative Commons licence, and indicate if changes were made. The images or other third party material in this article are included in the article's Creative Commons licence, unless indicated otherwise in a credit line to the material. If material is not included in the article's Creative Commons licence and your intended use is not permitted by statutory regulation or exceeds the permitted use, you will need to obtain permission directly from the copyright holder. To view a copy of this licence, visit http://creativecommons.org/licenses/by/4.0/. 


\section{Background}

Breast cancer constitutes a major cause of cancer deaths in females. Mammographic screening has been shown to be useful in the reduction of breast cancer mortality; however, the limitations of mammographic screening, particularly in women with dense or non-involuted breasts, are well established [1].

Contrast-enhanced spectral mammography (CESM) is a currently established technique in which contrast enhancement is used with digital mammography to depict tumor vascularity. CESM has been confirmed to be more sensitive than mammography for the diagnosis of breast cancer in dense breasts [2, 3].

CESM has a better resolution of a mammography over the MRI as it displays a better assessment of microcalcifications with its details. Furthermore, the images are acquired from one breast compression in a couple of seconds; therefore, there are no motion artifacts [3].

DWI is a fast functional non-contrast technique of the breast MR imaging without the costs and toxicity which occur with DCE-MRI. Breast cancers that are hidden mammographically or clinically and identified by DCE MRI are also detected on DWI and can discriminate them from benign breast lesions by accompanied apparent diffusion coefficient (ADC) mapping [4].

Diffusion-weighted (DW) MRI provides a promise in the detection of breast cancers that are mammographically occult and needs more studies to be used as an alternative supplemental breast cancer screening technique [5].

\section{Methods}

This is a prospective analytical study which included 40 breast lesions in 32 female patients having dense breasts; the age range was 29-72 years with mean age 46 years + 9.93 SD. The study was conducted in Baheya Charity Women's Cancer Hospital and Generalized Air Forces Hospital.

\section{Subjects}

Patients included in this study were adult females who underwent digital mammography which revealed dense breasts (American College of Radiology (ACR) C or D) and showed indeterminate or suspicious mammographic findings (BIRADS 3, 4, and 5) as well as patients had no detected mammographic abnormality (BIRADS 0) warranting further CESM/DW MRI assessment (Fig. 1).

\section{Contrast-enhanced spectral mammography technique}

Patients were examined by dual-energy CESM which was performed using Senographe Essential full-field digital mammography machine (GE Healthcare, Chalfont St-Giles, UK). A one-shot intravenous injection of nonionic contrast agent was administered with a dose of 1.5 $\mathrm{ml} / \mathrm{kg}$ body weight at a rate of $3 \mathrm{ml} / \mathrm{s}$. Then two subtracted images with contrast agent uptake information were obtained in mediolateral oblique (MLO) and cranio-caudal (CC) views.

The high-energy images were interpreted for the enhancement. Regarding patterns of enhancement seen by CESM, the lesions seen in subtracted images were classified and described into mass and non-mass enhancement lesions.

\section{MRI diffusion-weighted imaging technique}

MR imaging was performed on 1.5-T GE optima MR scanner release $450 \mathrm{~W}$ GE medical systems and 1.5-T scanner (Siemens machine Magnetom Aera, Siemens Medical Systems, Erlangen, Germany) with the patient in prone position, using a double breast coil. All acquisitions were performed in the axial plane. T2-weighted fast spin echo sequences were obtained. DWI was performed using a diffusion-weighted echo-planar imaging sequence with parallel imaging. Diffusion gradients were applied with $b=$ 0 and $1000 \mathrm{~s} / \mathrm{mm}^{2}$. ADC maps were automatically generated from DW images by the MR software.

T2 images were first assessed then diffusion-weighted images were reviewed to detect the lesion signal intensity, the lesions were considered either nonrestricted diffusion (low- to intermediate-intensity lesions) or restricted diffusion (high-intensity lesions).

Signal intensity was interpreted in a qualitative manner using $b$ value of $1000 \mathrm{~s} / \mathrm{mm}^{2}$. For apparent diffusion coefficient $(\mathrm{ADC})$ calculation, region of interest (ROI) was manually drawn on the ADC maps. Mean ADC for each lesion was calculated by the lowest ADC value from all examined ROIs within the lesion.

\section{CESM and DW MRI image evaluation}

Analysis and interpretation of lesions were detected in both CESM and DW images with determination of the BIRADS category of each lesion and the imaging findings were correlated with the final pathological diagnosis.

\section{Statistical analysis}

Data were analyzed using MedCalc $\odot$ version 18.2.1 (MedCalc@ Software bvba, Ostend, Belgium).

1. Qualitative data was presented by number and percentage; quantitative data was presented by mean and standard deviation.

2. ROC curve was used to detect validation of the diagnostic value of radiological tools.

3. Inter-method agreement for binary outcomes was examined by calculation of Bennett's prevalenceadjusted bias-adjusted kappa (PABAK).

4. A $P$ value of less than 0.05 was considered statistically significant. 

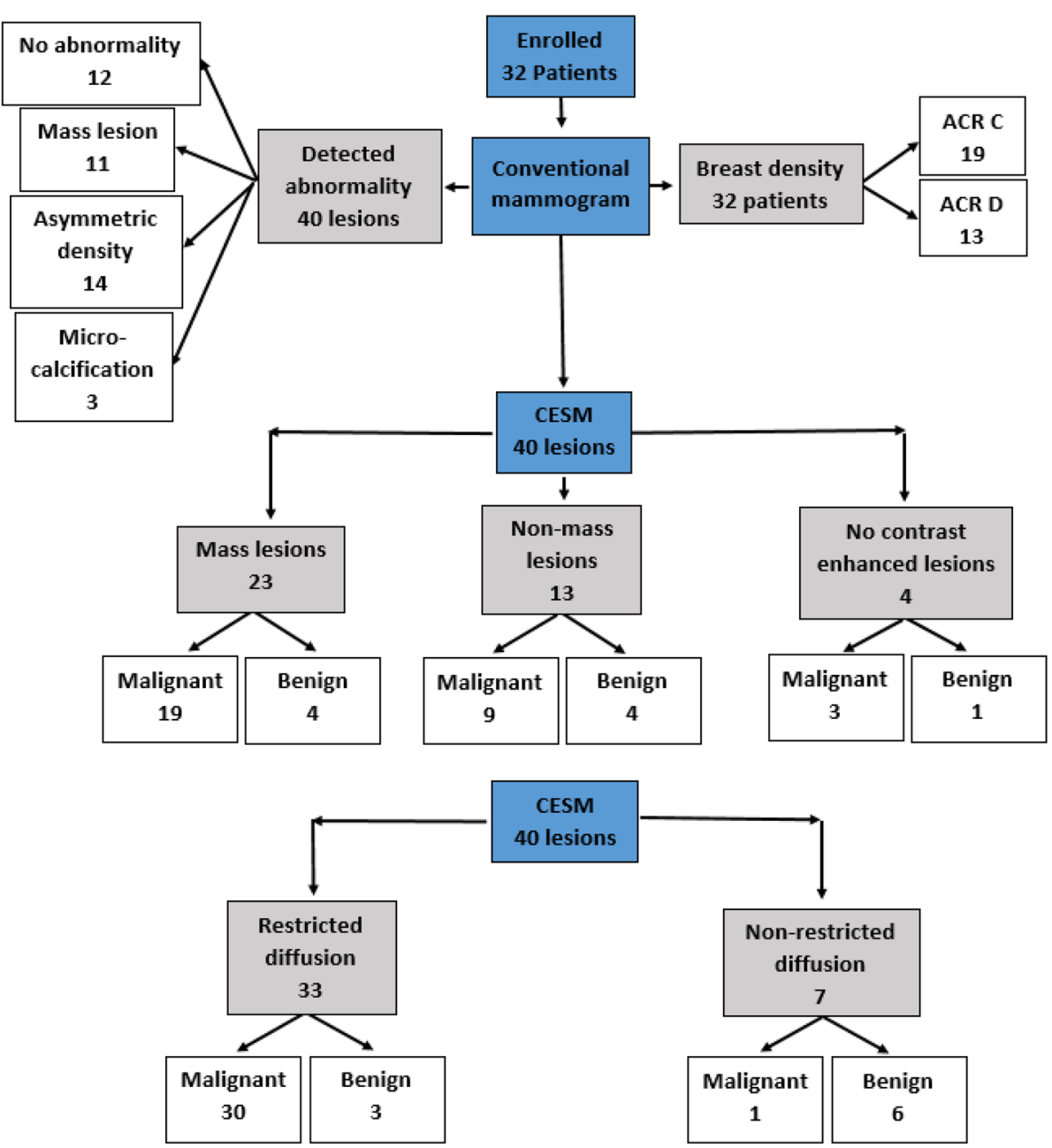

Fig. 1 A flowchart of the study

\section{Results}

The study included 32 female patients; their age range, main complaints and mammographical ACR classification into ACR C (heterogeneously dense breasts) and ACR D (extremely dense breasts) are demonstrated in Table 1.

The study showed 40 different lesions, as we considered cases which had more than one lesion in the same or both breasts as separate lesions. Their detailed description for the number and percentage of each pathological breast entity are illustrated in Table 2 .

From the thirty two cases, four cases (13.8\%) had multifocal breast lesions, and five cases (17.2\%) had multicentric malignant lesions. There were two lesions that were missed by CESM; however, all of them were diagnosed by DW MRI (Figs. 2 and 3). When comparing the sensitivity of CESM to DW MRI in the detection of multiple breast lesions, they were 88.8 and $100 \%$, respectively. The digital mammographic main findings were
Table 1 Characteristics of the study population

\begin{tabular}{llll}
\hline Variable & & Frequency & Percentage \\
\hline Age & Age $\leq 45$ years & 19 & $59.4 \%$ \\
& Age $>$ 45 years & 13 & $40.6 \%$ \\
Complaint & Mastalgia & 7 & $21.9 \%$ \\
& Breast lump & 14 & $43.8 \%$ \\
& Nipple discharge & 1 & $3.1 \%$ \\
& Bleeding per nipple & 3 & $9.4 \%$ \\
& Nipple erosion & 1 & $3.1 \%$ \\
& Check up & 4 & $12.5 \%$ \\
ACR category & ACR grade C & 19 & $6.2 \%$ \\
& ACR grade D & 13 & $59.4 \%$ \\
\hline
\end{tabular}


Table 2 Detailed pathological classification of the breast lesions

\begin{tabular}{llll}
\hline Pathological diagnosis & & Frequency & Percentage \\
\hline Malignant & Ductal carcinoma in situ & 1 & $2.5 \%$ \\
& Invasive ductal carcinoma & 17 & $42.5 \%$ \\
& Invasive lobular carcinoma & 6 & $15 \%$ \\
& Mixed ductal and lobular carcinoma & 2 & $5 \%$ \\
& Invasive tubular carcinoma & 2 & $5 \%$ \\
& Invasive carcinoma of no special type & 1 & $2.5 \%$ \\
& Invasive ductal \& tubular carcinoma & 2 & $5 \%$ \\
Benign & Fibroadenosis & 3 & $7.5 \%$ \\
& Fibroadenoma & 4 & $10 \%$ \\
& Hamartoma & 1 & $2.5 \%$ \\
& Fibrosis & 1 & $2.5 \%$ \\
\end{tabular}

correlated to the histopathological results and demonstrated in Table 3.

\section{CESM findings}

CESM classified the lesions into twenty three mass lesions and thirteen non-mass lesions, and four lesions showed no contrast enhancement. CESM findings were correlated to the histopathological results as illustrated in Table 3. The lesions were then described in mass lesions regarding margin of the mass, pattern of enhancement, and intensity of enhancement, while non-mass lesions were described regarding distribution, pattern of enhancement, and intensity of enhancement then correlated versus the histopathological diagnosis as illustrated in Table 4 .

There were four lesions that showed no contrast enhancement; by digital mammography, they showed asymmetrical density apart from one lesion which showed pleomorphic microcalcifications (Fig. 4). Then the detected breast lesions were categorized according to BIRADS classification as illustrated in Table 5 .

CESM showed six false-positive lesions; three fibroadenomas, one fibroadenosis, one hamartoma and one post-operative fibrosis (Fig. 5). Also, it showed three false-negative lesions-one IDC (Fig. 2) and two lesions in the same case were proved pathologically to be invasive ductal and tubular carcinomas (Fig. 3).

There were four lesions which showed no contrast enhancement; one lesion proved to be benign (Fig. 7), and three lesions were pathologically proved to be malignant. They were one DCIS (Fig. 4), one mixed invasive ductal and lobular carcinoma, and one invasive ductal and tubular carcinoma (Fig. 3).

ROC curve of CESM for the probability of malignancy using BIRADS showed area under the curve to be 0.579 where the sensitivity and specificity were $90.32 \%$, and $33.33 \%$, respectively, total accuracy $77.5 \%$, PPV $82.3 \%$, and NPV of $50 \%$ (Table 6).

\section{DW MRI findings}

The detected breast lesions were classified by T2 signal intensity into low $\mathrm{T} 2$, isointense $\mathrm{T} 2$, and high $\mathrm{T} 2$ signal intensities. According to the lesion characteristics in diffusion-weighted image, the breast lesions were classified into thirty-three restricted diffusion lesions and seven non-restricted diffusion lesions, then they correlated to the histopathological diagnosis as illustrated in Table 7.

$\mathrm{ADC}$ value of the lesions were correlated to the histopathological diagnosis, where the mean $\mathrm{ADC}$ value of the benign lesions was $1.5 \pm 0.42 \times 10^{-3} \mathrm{~s} / \mathrm{mm}^{2}$ and that of the malignant lesions was $0.91+0.18 \times 10^{-3} \mathrm{~s} / \mathrm{mm}^{2}$.

According to the DW MRI characteristics of the breast lesions, they were categorized according to BIRADS classification as illustrated in Table 5.

This study showed one false-negative lesion by DW MRI, which pathologically proved to be $I L C$ (Fig. 6) and three false-positive lesions, one fibroadenoma (Fig. 7) and two fibroadenosis (Fig. 8).

ROC curve of DW MRI for the probability of malignancy using BIRADS showed that area under the curve is about 0.762 where the sensitivity and specificity were 96.77 and $66.67 \%$, respectively, total accuracy of $90 \%$, PPV of $90.91 \%$, and NPV of $85.71 \%$ (Table 6).

ROC curve for probability of malignancy using ADC value showed that area under the curve was about 0.815 . A cutoff value of $\leq 1.1 \times 10^{-3} \mathrm{~s} / \mathrm{mm}^{2}$ had a sensitivity of $96.77 \%$, specificity of $66.67 \%$, total accuracy of $92.5 \%$, PPV of $96.77 \%$, and NPV of $55.55 \%$ (Table 6).

Comparing the detected lesions by CESM to that of DW MRI are demonstrated in Table 8.

\section{Discussion}

This study presented four multifocal cases; one of them was missed by CESM, while all of them were diagnosed by DW MRI. Furthermore, our study revealed five cases having multicentric malignant lesions; one of them was 

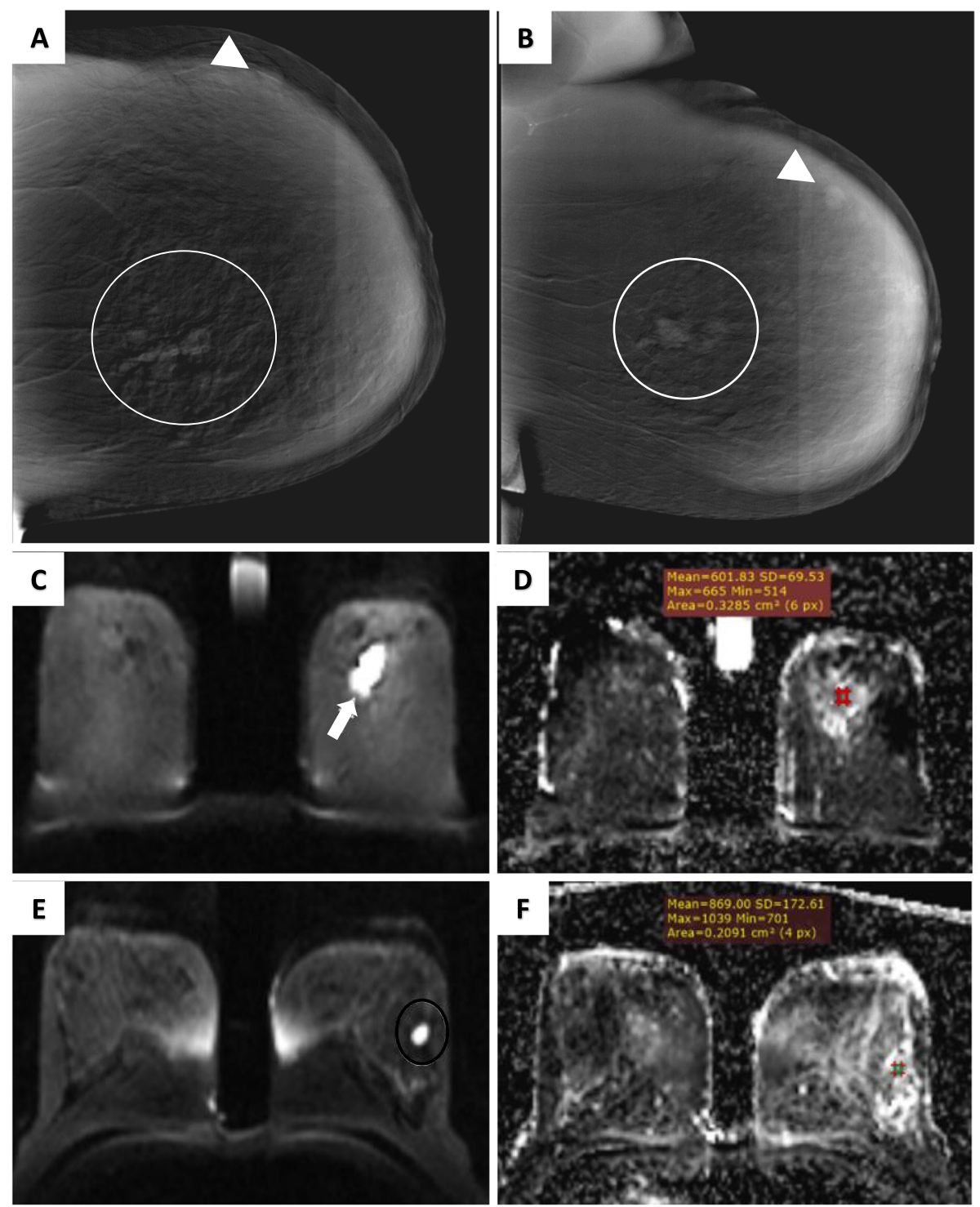

Fig. 2 A 62-year-old female patient presented with left breast lump. a and b CESM CC and MLO views of the left breast show central inner region (white circles) irregular moderate heterogeneous enhanced mass (BIRADS 4) and UOQ (white arrowheads) lobulated faint homogenous enhanced mass (BIRADS 3). $\mathbf{c}$ and $\mathbf{d}$ DWI and ADC cuts of the left breast show upper central region mass eliciting restricted diffusion (white arrow) with corresponding mean ADC value of $0.6 \times 10^{-3} \mathrm{~s} / \mathrm{mm}^{2}$ (BIRADS 4). e and $\mathbf{f}$ DWI and ADC cuts show another similar UOQ mass lesion (black circle) with mean ADC value of $0.8 \times 10^{-3} \mathrm{~s} / \mathrm{mm}^{2}$ (BIRADS 4). Tru-cut biopsy and simple mastectomy of the left breast revealed multicentric invasive ductal carcinoma, grade III which matched the DW MRI findings

missed by CESM, and all of them were detected by DW MRI. Thus, the sensitivity of DW MRI to detect multiple breast lesions was $100 \%$ which is higher than that of CESM 88.8\%.

In concordance with Jochelson et al.'s study, they said that breast cancers are often multifocal and multicentric. Additional foci of ipsilateral breast cancer are often mammographically occult and are identified more frequently with MR imaging. On the other hand, Luczyn'ska et al.'s study found that CESM may provide fast and accurate breast lesion detection and characterization $[6,7]$.
CESM mass lesions in this study showed the most common features that described malignant lesions were noncircumscribed margins (speculated or irregular) (69.5\%), heterogeneous contrast enhancement $(47.9 \%)$, and rim enhancement (26.1\%). This was matching Schnall et al.'s study which showed that the most important feature of image interpretation is the characterization of the focal mass margin. Irregular or speculated margins have a positive predictive value (PPV) of 84-91\%. Rim-like enhancement highly correlates with a cancer diagnosis (PPV, 84\%). Also, intense (43.5\%) and moderate contrast 

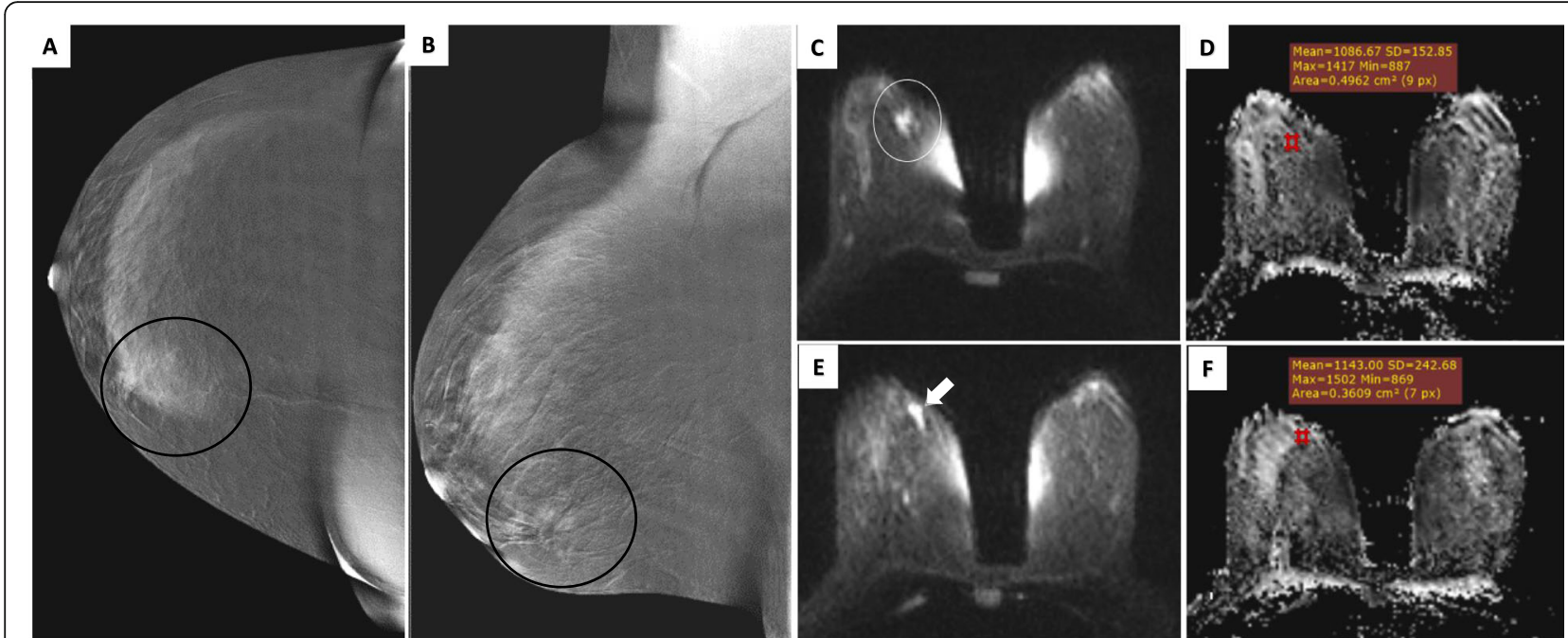

Fig. 3 A 44-year-old female patient presented with right breast lump. a and b CESM CC and MLO views of the right breast show LIQ (black circles) focal faintly enhanced clumped non-mass lesion (BIRADS 3). $\mathbf{c}$ and $\mathbf{d}$ DWI and ADC cuts of right breast show LIQ mass eliciting restricted diffusion (white circle) with corresponding mean ADC value of $1 \times 10^{-3} \mathrm{~s} / \mathrm{mm}^{2}$ (BIRADS 4). e and $\mathbf{f}$ DWI and ADC cuts show another similar adjacent mass (white arrow) with mean ADC value of $1.1 \times 10^{-3} \mathrm{~s} / \mathrm{mm}^{2}$ (BIRADS 4). Tru-cut biopsy revealed right breast multifocal invasive ductal and tubular carcinoma which matched the DW MRI findings

enhancements (30.4\%) were common findings of the malignant lesions in this study, and this was in concordance with Kaur et al.'s study, which said that in CESM, a mass with moderate or intense enhancement is suspicious of malignant transformation $[1,8]$.

Table 3 Cross tabulation showing the main classification of digital mammographic and CESM findings versus the histopathological diagnosis

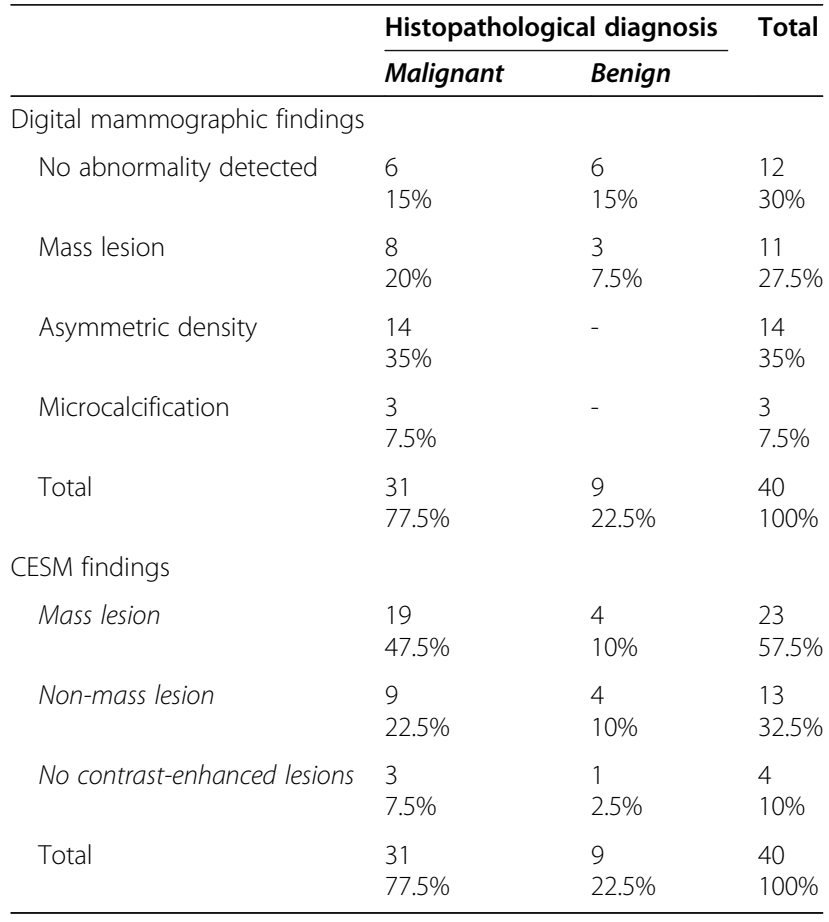

In the study, CESM non-mass lesions showed that the most common features that described malignant lesions were focal and segmental distribution of non-mass lesions $(23.07 \%$ for each), regional distribution (15.38\%), clumped contrast enhancement (38.46\%), heterogeneous contrast enhancement (30.76\%), and intense contrast enhancement (38.46\%).

In contrast to Schnall et al.'s study, a moderate to marked non-mass regional enhancement provides a PPV of $59 \%$ in malignant lesion detection. Stippled enhancement was found that it has a low incidence of malignancy (25\%), while clumped, heterogeneous, and homogeneous enhancements were found to have a $60 \%, 53 \%$, and $67 \%$ likelihood of cancer, respectively [8].

In the current study, CESM showed six false-positive lesions (19.3\% false-positive rate), three fibroadenomas, one fibroadenosis, one hamartoma, and one postoperative fibrosis.

In contrast to Luczyn'ska et al. and Muller et al.'s studies, there was a relatively high rate $(20 \%)$ of falsepositive results and no false-negative findings with CESM. Benign lesions, such as fibroadenomas, fibrosclerosis, hamartoma, intraductal papillomas, and phyllodes tumors had shown contrast enhancement $[7,9]$.

In this study, CESM showed three false-negative lesions (33.3\% false-negative rate); one $I D C$ and two lesions invasive ductal and tubular carcinomas in the same case. Furthermore, there was one DCIS case which showed no contrast enhancement; however, the presence of pleomorphic microcalcifications raised the 
Table 4 Cross tabulation showing CESM morphology descriptors of the mass and non-mass lesions versus the histopathological diagnosis

\begin{tabular}{|c|c|c|c|c|}
\hline \multirow[t]{2}{*}{ CESM findings } & & \multicolumn{2}{|c|}{ Histopathological diagnosis } & \multirow[b]{2}{*}{ Total } \\
\hline & & Malignant & Benign & \\
\hline \multicolumn{5}{|l|}{ Descriptors of mass lesions } \\
\hline \multirow[t]{3}{*}{ Margin } & Circumscribed (lobulated) & $\begin{array}{l}1 \\
4.34 \%\end{array}$ & $\begin{array}{l}1 \\
4.34 \%\end{array}$ & $\begin{array}{l}2 \\
8.7 \%\end{array}$ \\
\hline & Partial circumscribed & $\begin{array}{l}2 \\
8.7 \%\end{array}$ & $\begin{array}{l}- \\
-\end{array}$ & $\begin{array}{l}2 \\
8.7 \%\end{array}$ \\
\hline & Non-circumscribed (irregular or speculated) & $\begin{array}{l}16 \\
69.5 \%\end{array}$ & $\begin{array}{l}3 \\
13 \%\end{array}$ & $\begin{array}{l}19 \\
82.6 \%\end{array}$ \\
\hline \multirow[t]{3}{*}{ Pattern of enhancement } & Homogenous & $\begin{array}{l}2 \\
8.7 \%\end{array}$ & $\begin{array}{l}1 \\
4.3 \%\end{array}$ & $\begin{array}{l}3 \\
13 \%\end{array}$ \\
\hline & Heterogeneous & $\begin{array}{l}11 \\
47.9 \%\end{array}$ & $\begin{array}{l}3 \\
13 \%\end{array}$ & $\begin{array}{l}14 \\
60.9 \%\end{array}$ \\
\hline & Ring enhancement & $\begin{array}{l}6 \\
26.1 \%\end{array}$ & - & $\begin{array}{l}6 \\
26.1 \%\end{array}$ \\
\hline \multirow[t]{3}{*}{ Intensity of enhancement } & Faint & $\begin{array}{l}2 \\
8.7 \%\end{array}$ & $\begin{array}{l}1 \\
4.3 \%\end{array}$ & $\begin{array}{l}3 \\
13 \%\end{array}$ \\
\hline & Moderate & $\begin{array}{l}7 \\
30.4 \%\end{array}$ & $\begin{array}{l}2 \\
8.7 \%\end{array}$ & $\begin{array}{l}9 \\
39.1 \%\end{array}$ \\
\hline & Intense & $\begin{array}{l}10 \\
43.5 \%\end{array}$ & $\begin{array}{l}1 \\
4.3 \%\end{array}$ & $\begin{array}{l}11 \\
47.9 \%\end{array}$ \\
\hline \multicolumn{5}{|c|}{ Descriptors of non-mass lesions } \\
\hline \multirow[t]{4}{*}{ Distribution } & Focal & $\begin{array}{l}3 \\
23.078 \%\end{array}$ & $\begin{array}{l}3 \\
23.078 \%\end{array}$ & $\begin{array}{l}6 \\
46.16 \%\end{array}$ \\
\hline & Segmental & $\begin{array}{l}3 \\
23.07 \%\end{array}$ & $\begin{array}{l}- \\
-\end{array}$ & $\begin{array}{l}3 \\
23.07 \%\end{array}$ \\
\hline & Regional & $\begin{array}{l}2 \\
15.38 \%\end{array}$ & $\begin{array}{l}1 \\
7.7 \%\end{array}$ & $\begin{array}{l}3 \\
23.07 \%\end{array}$ \\
\hline & Diffuse & $\begin{array}{l}1 \\
7.7 \%\end{array}$ & $\begin{array}{l}- \\
-\end{array}$ & $\begin{array}{l}1 \\
7.7 \%\end{array}$ \\
\hline \multirow[t]{3}{*}{ Pattern of enhancement } & Heterogeneous & $\begin{array}{l}4 \\
30.76 \%\end{array}$ & $\begin{array}{l}1 \\
7.7 \%\end{array}$ & $\begin{array}{l}5 \\
38.46 \%\end{array}$ \\
\hline & Clumped & $\begin{array}{l}5 \\
38.46 \%\end{array}$ & $\begin{array}{l}2 \\
15.38 \%\end{array}$ & $\begin{array}{l}7 \\
53.84 \%\end{array}$ \\
\hline & Nodular & $\begin{array}{l}- \\
-\end{array}$ & $\begin{array}{l}1 \\
7.7 \%\end{array}$ & $\begin{array}{l}1 \\
7.7 \%\end{array}$ \\
\hline \multirow[t]{3}{*}{ Intensity of enhancement } & Faint & $\begin{array}{l}2 \\
15.38 \%\end{array}$ & $\begin{array}{l}- \\
-\end{array}$ & $\begin{array}{l}2 \\
15.38 \%\end{array}$ \\
\hline & Moderate & $\begin{array}{l}2 \\
15.38 \%\end{array}$ & $\begin{array}{l}3 \\
23.07 \%\end{array}$ & $\begin{array}{l}5 \\
38.46 \%\end{array}$ \\
\hline & Intense & $\begin{array}{l}5 \\
38.46 \%\end{array}$ & $\begin{array}{l}1 \\
7.7 \%\end{array}$ & $\begin{array}{l}6 \\
46.16 \%\end{array}$ \\
\hline
\end{tabular}

suspicion of the diagnosis. This was in agreement with Fallenberg et al.'s study which reported that the low-energy image of CESM is comparable with standard mammography with regard to the visualization of microcalcifications [10].

CESM in this study presented two postoperative cases; one of them was pathologically proved to be recurrent $I D C$, while the other one showed suspicious contrast enhancement by CESM and revealed pathologically to be postoperative fibrosis.
In line with Helal et al.'s study, they had nine falsepositive cases that were found out in the comparison of the CESM diagnoses with the histopathology results. These cases were wrongly diagnosed because the operative bed showed areas of enhancement, but these enhancements were caused by benign postoperative sequel [11].

This DW MRI study showed that the mean ADC value of the benign lesions was $1.5+0.42 \times 10^{-3} \mathrm{~s} / \mathrm{mm}^{2}$ which is higher than that of the malignant lesions which was $0.91 \pm 0.18 \times 10^{-3} \mathrm{~s} / \mathrm{mm}^{2}$. This was in concordance with 

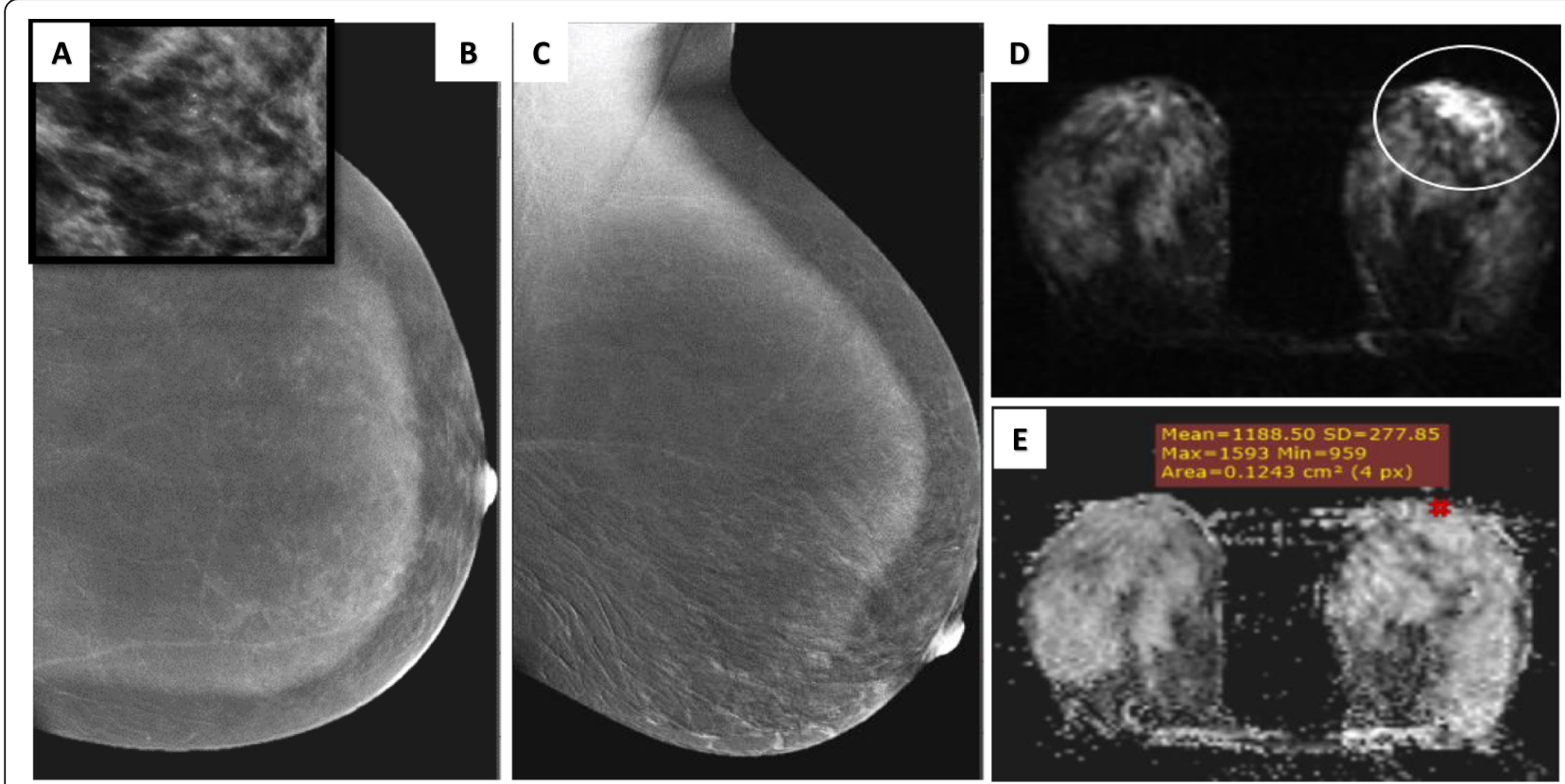

Fig. 4 A 31-year-old female patient presented with left breast nipple erosions. a Magnified mammographic image of the left breast shows scattered pleomorphic microcalcifications at the UOQ. $\mathbf{b}$ and $\mathbf{c} C C$ and MLO views of the left breast show no significant contrast enhancement (BIRADS 4). $\mathbf{d}$ and $\mathbf{e}$ DWI and ADC cuts show left breast retroareolar (white circle) linear mass lesion reaching the nipple eliciting restricted diffusion with corresponding mean ADC value of $1.1 \times 10^{-3} \mathrm{~s} / \mathrm{mm}^{2}$ (BIRADS 5). Tru-cut biopsy of the left breast revealed Paget's disease of the nipple with associated high-grade DCIS of the major lactiferous duct which matched the DW MRI findings

Moukhtar and Abo El Maati's study, where they reported that the mean ADC value of all benign lesions was $1.41 \pm 0.36 \times 10^{-3} \mathrm{~s} / \mathrm{mm}^{2}$, which was higher than the mean ADC of all malignant lesions $(1.05 \pm 0.30 \times$ $\left.10^{-3} \mathrm{~s} / \mathrm{mm}^{2}\right)$ [12].

Our study showed that a cutoff $\mathrm{ADC}$ value $\leq 1.1 \times$ $10^{-3} \mathrm{~s} / \mathrm{mm}^{2}$ at $b$ value of $1000 \mathrm{~s} / \mathrm{mm}^{2}$ had a sensitivity of $96.77 \%$, specificity of $66.67 \%$, PPV of $96.77 \%$, NPV of
$55.55 \%$, and with an overall total accuracy of $92.5 \%$. This was in concordance with Moukhtar and Abo El Maati's study which showed that the optimal cutoff value to discriminate benign from malignant lesions was $1.25 \times 10^{-3}$ $\mathrm{s} / \mathrm{mm}^{2}$, with a sensitivity of $82 \%$, a specificity of $68 \%$, and an overall accuracy of $78 \%$ [13].

This study showed that IDCs had a mean ADC value $\left(0.92 \pm 0.14 \times 10^{-3} \mathrm{~s} / \mathrm{mm}^{2}\right)$ which was slightly lower than

Table 5 Cross tabulation showing the diagnostic accuracy of CESM and DW MRI tested versus histopathological diagnosis as the gold standard for lesion classification

\begin{tabular}{|c|c|c|c|}
\hline & \multicolumn{2}{|c|}{ Histopathological diagnosis } & \multirow[t]{2}{*}{ Total } \\
\hline & Malignant & Benign & \\
\hline \multicolumn{4}{|l|}{ BIRADS classification by CESM } \\
\hline Probably benign (BIRADS 1-3) & $\begin{array}{l}3 \\
7.5 \%\end{array}$ & $\begin{array}{l}3 \\
7.5 \%\end{array}$ & $\begin{array}{l}6 \\
15 \%\end{array}$ \\
\hline Probably malignant (BIRADS 4-5) & $\begin{array}{l}28 \\
70 \%\end{array}$ & $\begin{array}{l}6 \\
15 \%\end{array}$ & $\begin{array}{l}34 \\
85 \%\end{array}$ \\
\hline Total & $\begin{array}{l}31 \\
77.5 \%\end{array}$ & $\begin{array}{l}9 \\
22.5 \%\end{array}$ & $\begin{array}{l}40 \\
100 \%\end{array}$ \\
\hline \multicolumn{4}{|l|}{ BIRADS classification by DW MRI } \\
\hline Probably benign (BIRADS 1-3) & $\begin{array}{l}1 \\
2.5 \%\end{array}$ & $\begin{array}{l}6 \\
15 \%\end{array}$ & $\begin{array}{l}7 \\
17.5 \%\end{array}$ \\
\hline Probably malignant (BIRADS 4-5) & $\begin{array}{l}30 \\
75 \%\end{array}$ & $\begin{array}{l}3 \\
7.5 \%\end{array}$ & $\begin{array}{l}33 \\
82.5 \%\end{array}$ \\
\hline Total & $\begin{array}{l}31 \\
77.5 \%\end{array}$ & $\begin{array}{l}9 \\
22.5 \%\end{array}$ & $\begin{array}{l}40 \\
100 \%\end{array}$ \\
\hline
\end{tabular}



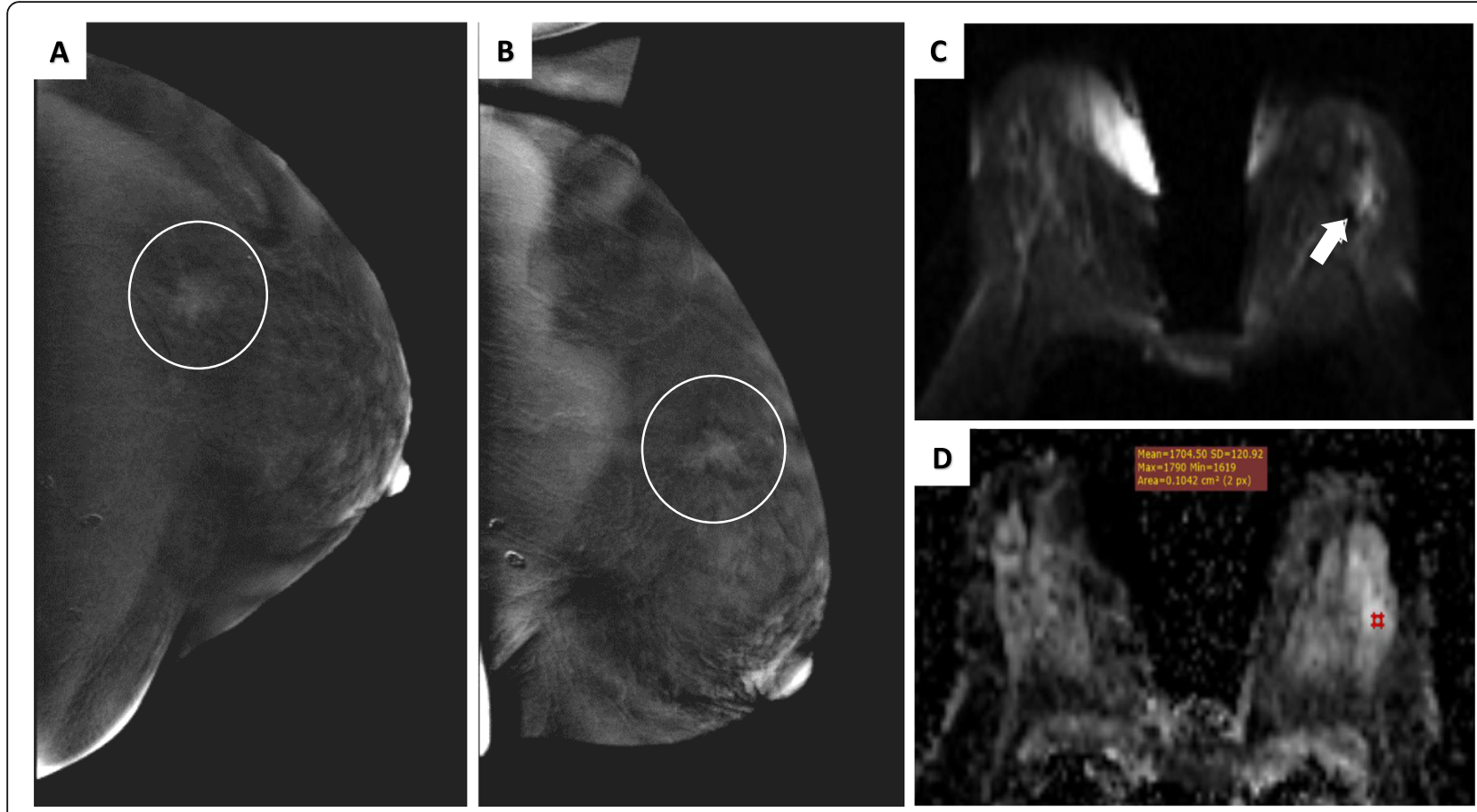

Fig. 5 A 45-year-old female patient for postoperative follow-up 1 year after left BCS. a and $\mathbf{b}$ CESM CC and MLO views of the left breast show UOQ (white circles) speculated moderately enhanced mass lesion (BIRADS 4). $\mathbf{c}$ and $\mathbf{d}$ DWI and ADC cuts of the left breast show UOQ (white arrow) irregularly shaped mass eliciting non-restricted diffusion with corresponding mean ADC value of $1.7 \times 10^{-3} \mathrm{~s} / \mathrm{mm}^{2}$ (BIRADS 3). Tru-cut biopsy of the left breast revealed UOQ fibrosis with no atypia or malignancy which matched the DW MRI findings

that of $I L C s$ which showed mean ADC value $(0.93+$ $\left.0.29 \times 10^{-3} \mathrm{~s} / \mathrm{mm}^{2}\right)$. Our study had only one DCIS lesion with $\mathrm{ADC}$ value relatively higher than that of the invasive lesions; it was $1.1 \times 10^{-3} \mathrm{~s} / \mathrm{mm}^{2}$.

Woodhams et al.'s study reported that because of their higher cellularity, most of IDCs show higher signal

Table 6 Comparison between the diagnostic accuracy of CESM, DW MRI and ADC value

\begin{tabular}{llll}
\hline & CESM & DW MRI & ADC value \\
\hline True positive & 28 & 30 & \\
True negative & $70 \%$ & $75 \%$ & \\
False positive & 3 & 6 & \\
& $7.5 \%$ & $15 \%$ & \\
False negative & 6 & 3 & \\
& $15 \%$ & $7.5 \%$ & \\
Sensitivity & 3 & 1 & \\
Specificity & $7.5 \%$ & $2.5 \%$ & $96.77 \%$ \\
Total accuracy & $90.32 \%$ & $96.77 \%$ & $77.78 \%$ \\
Disease prevalence & $33.33 \%$ & $66.67 \%$ & $92.50 \%$ \\
Positive predictive value (PPV) & $82.35 \%$ & $90.91 \%$ & $93.75 \%$ \\
Negative predictive value (NPV) & $50.00 \%$ & $85.71 \%$ & $87.50 \%$ \\
Positive likelihood ratio (LR+) & 1.35 & 2.90 & 4.35 \\
Negative likelihood ratio (LR-) & 0.29 & 0.05 & 0.04 \\
\hline
\end{tabular}

intensity and lower ADC values than that of benign tumors and normal breast parenchyma on diffusionweighted images [12].

In this study, DWI showed one false-negative lesion $(2.5 \%$ false-negative rate); it was $I L C$ which showed non-restricted diffusion with high ADC value of $1.5 \times 10^{-3} \mathrm{~s} / \mathrm{mm}^{2}$.

Table 7 Cross tabulation showing the diagnostic accuracy of T2 signal intensity and DW MRI versus histopathological diagnosis

\begin{tabular}{|c|c|c|c|}
\hline & \multicolumn{2}{|c|}{ Histopathological diagnosis } & \multirow[t]{2}{*}{ Total } \\
\hline & Malignant & Benign & \\
\hline \multicolumn{4}{|c|}{$\mathrm{T} 2$ signal intensity of the breast lesions } \\
\hline Low T2 signal & $\begin{array}{l}18 \\
45 \%\end{array}$ & $\begin{array}{l}1 \\
2.5 \%\end{array}$ & $\begin{array}{l}19 \\
47.5 \%\end{array}$ \\
\hline Isointense T2 signal & $\begin{array}{l}13 \\
32.5 \%\end{array}$ & $\begin{array}{l}7 \\
17.5 \%\end{array}$ & $\begin{array}{l}20 \\
50 \%\end{array}$ \\
\hline High T2 signal & - & $\begin{array}{l}1 \\
2.5 \%\end{array}$ & $\begin{array}{l}1 \\
2.5 \%\end{array}$ \\
\hline Total & $\begin{array}{l}31 \\
77.5 \%\end{array}$ & $\begin{array}{l}9 \\
22.5 \%\end{array}$ & $\begin{array}{l}40 \\
100 \%\end{array}$ \\
\hline \multicolumn{4}{|c|}{ Classification of breast lesions by DW MRI } \\
\hline Restricted diffusion & $\begin{array}{l}30 \\
75 \%\end{array}$ & $\begin{array}{l}3 \\
7.5 \%\end{array}$ & $\begin{array}{l}33 \\
82.5 \%\end{array}$ \\
\hline Non-restricted diffusion & $\begin{array}{l}1 \\
2.5 \%\end{array}$ & $\begin{array}{l}6 \\
15 \%\end{array}$ & $\begin{array}{l}7 \\
17.5 \%\end{array}$ \\
\hline Total & $\begin{array}{l}31 \\
77.5 \%\end{array}$ & $\begin{array}{l}9 \\
22.5 \%\end{array}$ & $\begin{array}{l}40 \\
100 \%\end{array}$ \\
\hline
\end{tabular}



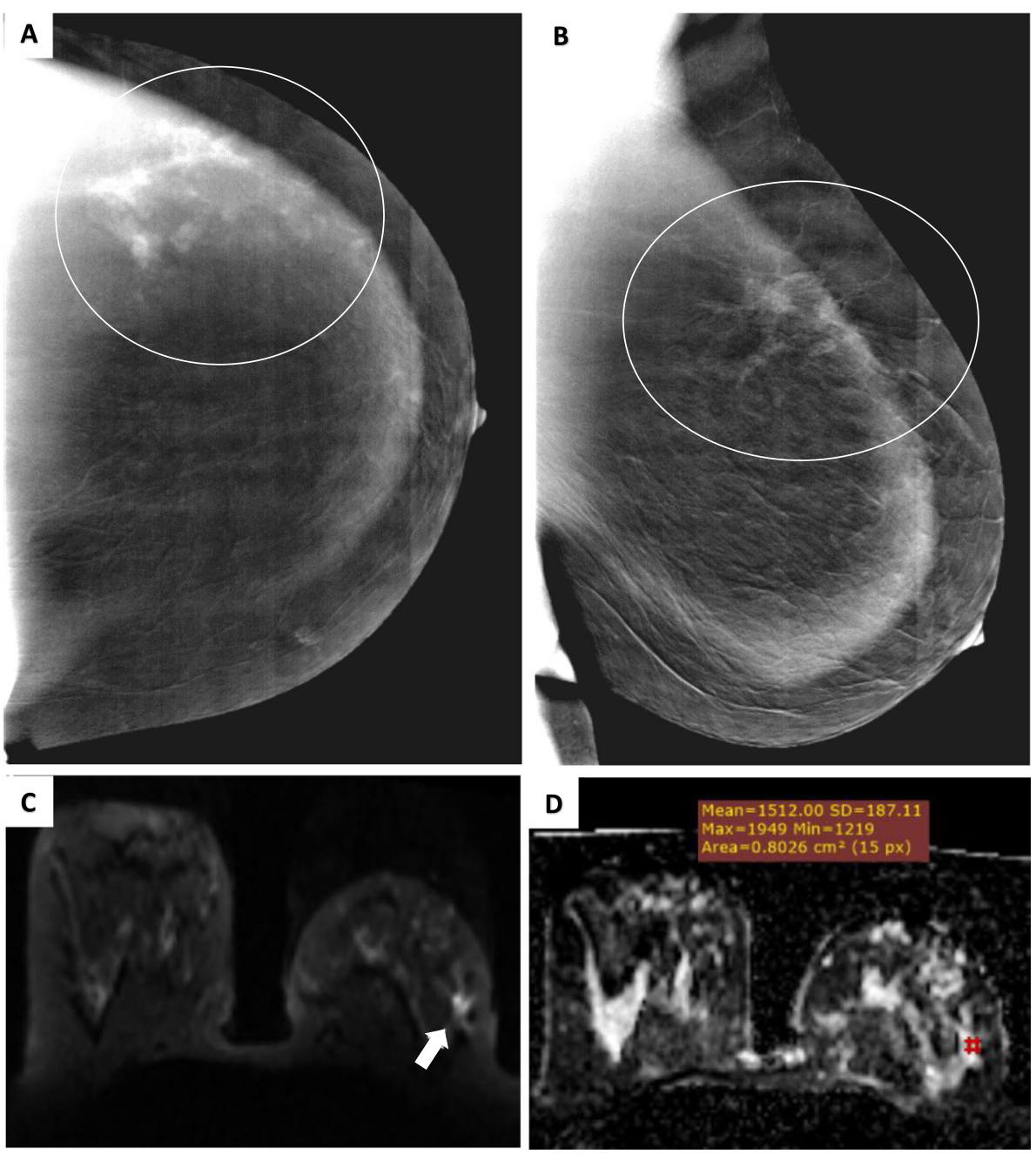

Fig. 6 A 44-year-old female patient presented for check-up. a and b CESM CC and MLO views of the left breast show UOQ (white circles) segmental clumped moderate contrast enhancement non-mass lesion (BIRADS 4). $\mathbf{c}$ and $\mathbf{d}$ DWI and ADC cuts of the left breast show UOQ (white arrow) mass with non-restricted diffusion and corresponding mean ADC value of $1.5 \times 10^{-3} \mathrm{~s} / \mathrm{mm}^{2}$ (BIRADS 3). Tru-cut biopsy of the left breast revealed UOQ invasive lobular carcinoma grade II with extensive LCIS which matched the CESM findings

According to Woodhams et al.'s study, invasive lobular carcinoma represents a diagnostic challenge at MR imaging as well as its size may be underestimated at diffusion-weighted imaging; this inaccuracy may be due to the spread of infiltrating cells [12].

DWI in this study showed three false-positive lesions (33.3\% false-positive rate); one fibroadenoma and two fibroadenosis. Fibroadenoma showed restricted diffusion with low ADC value $0.8 \times 10^{-3} \mathrm{~s} / \mathrm{mm}^{2}$. Two fibroadenosis lesions showed restricted diffusion as well as low ADC value 1.1 and $1.2 \times 10^{-3} \mathrm{~s} / \mathrm{mm}^{2}$.

According to Pereira et al.'s study, fibroadenomas are supposed to have high rates of diffusion and ADC values owing to their stromal myxoid changes and consequently increased mobility of water. However, fibroadenomas with an abundant fibrous component have lower
ADC values. Additionally, fibrocystic disease, which is characterized by considerable degrees of fibrosis and proliferation, may have ADC values in the range of malignant lesions [14].

This study revealed that the sensitivity and specificity of the DW MRI to detect malignant lesions were 96.77 and $66.67 \%$, respectively, PPV of $90.91 \%$, and NPV of $85.71 \%$ with a total accuracy of $90 \%$.

This was in concordance with Partridge and McDonald's study which established that the diagnostic performance of quantitative breast DWI exhibited pooled sensitivity of $84 \%$ and specificity of $79 \%$ [4].

In this study, the diagnostic accuracy of DW MRI was higher than that of CESM where the sensitivity of DW MRI was $96.77 \%$ as compared with $90.32 \%$ in CESM. The specificity of DW MRI was $66.67 \%$ as compared 


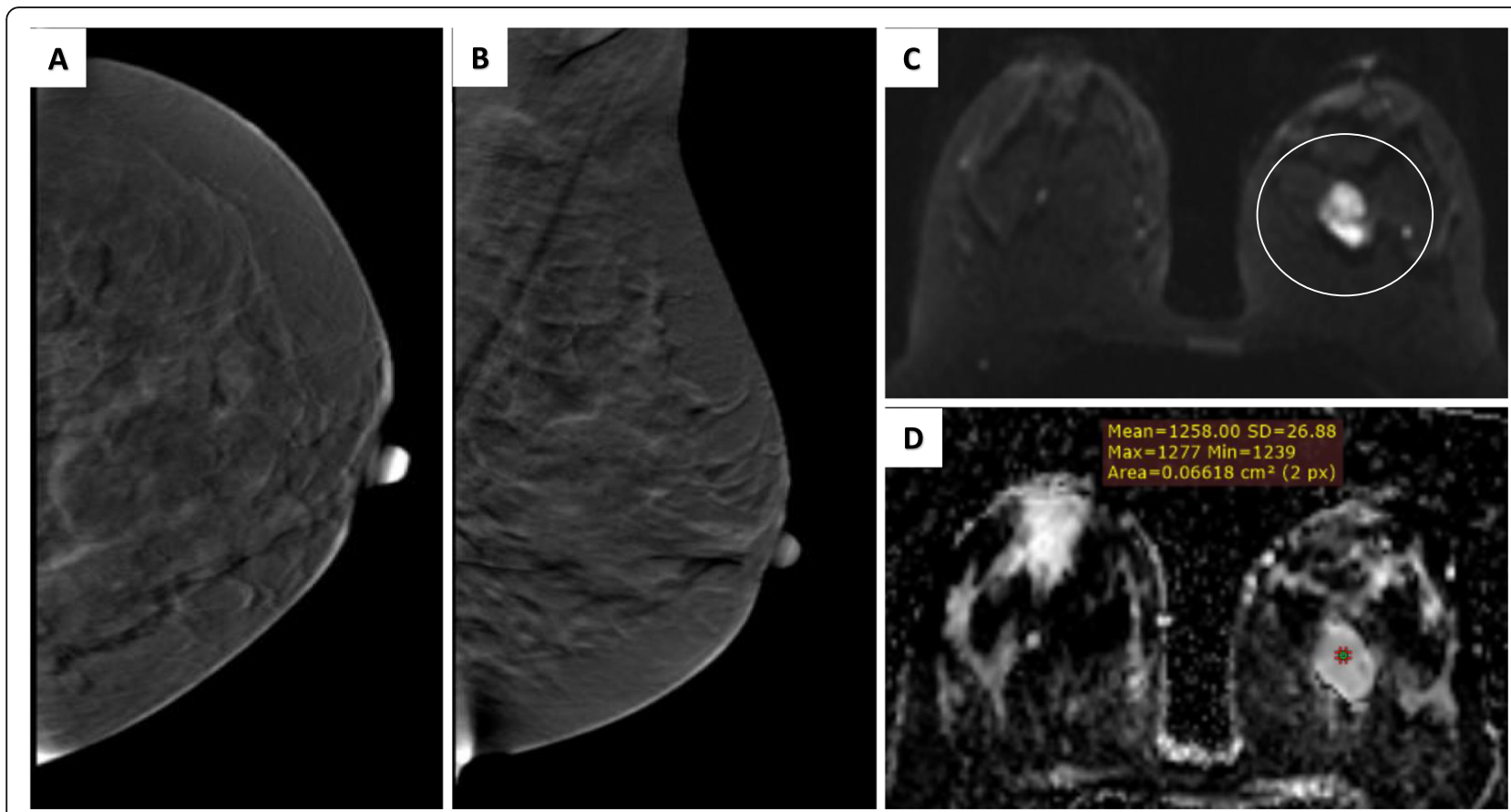

Fig. 7 A 37-year-old female patient presented with right breast lump. a Magnified mammographic image for the pleomorphic microcalcifications at UOQ of the right breast. $\mathbf{b}$ and $\mathbf{c}$ CESM CC and MLO views of the right breast show UOQ diffuse non-mass heterogeneous intense enhancement (white arrowheads) (BIRADS 5). $\mathbf{d}$ and $\mathbf{e}$ CESM CC and MLO views of the left breast show UOQ (black circles) regional non-mass moderate nodular parenchymal enhancement (BIRADS 3). $\mathbf{f}$ and $\mathbf{g}$ DWI and ADC cuts show right breast is nearly totally occupied by a diffuse infiltrative mass lesion (white arrows) eliciting restricted diffusion with corresponding mean ADC value of $0.9 \times 10^{-3} \mathrm{~s} / \mathrm{mm}^{2}$ (BIRADS 5). $\mathbf{h}$ and $\mathbf{i}$ DWl and ADC cuts of the left breast also show UOQ (white circle) similar mass with mean ADC value of $1.2 \times 10^{-3} \mathrm{~s} / \mathrm{mm}^{2}$ (BIRADS 4). Tru-cut biopsies revealed right breast invasive lobular carcinoma grade II and left breast fibroadenosis, no malignancy which matched the CESM findings

with 33.33\% in CESM. The total accuracies were 90 and $77.5 \%$, respectively. Also PPV and NPV of DW MRI were 90.91 and $85.71 \%$ as compared with 82.35 and $50.00 \%$ in CESM, respectively.

This was in concordance with Barra et al.'s study; among the 25 patients who had residual lesions, 19 were positive by CESM, and 23 were positive by MRI. Higher sensitivity was found by MRI (92\%) in contrast to $76 \%$ in CESM. Also PPV and NPV were higher for MRI comparable to CESM; they were 95 and $75 \%$ as compared with 92 and $53.8 \%$, respectively [15].

Our study had several limitations. First, our study population was small. Second, pre- and postmenopausal women were included and were examined in different phases of the menstrual cycle. Third, most cases were collected from the cancer breast center, so the negative lesions were small in number. Finally, women with no suspicious lesions at conventional mammography or CESM mostly did not undergo DW MRI and thus were not included in this study.

\section{Conclusion}

Dual-energy contrast-enhanced digital mammography is a useful technique in identification of lesions in mammographically dense breasts and capable of demonstrating lesions that are not visible by standard mammography. In comparison with MRI, CESM can detect microcalcifications easily, and there are no limitations as with MRI in terms of the ferromagnetic effect and machine design.

DW MRI technique is a diagnostic technique that enables accurate detection of malignant breast lesions without need for the contrast media injection, and it avoids the irradiation exposure.

CESM and DWI demonstrated good overall diagnostic accuracy and correlation in lesion size estimation in dense breast patients. However, DW MRI has a higher diagnostic accuracy than CESM for the detection of malignant breast lesions in dense breasts with a higher sensitivity, specificity, total accuracy, negative predictive value, and positive predictive value as well as the detection of multiple lesions.

\section{Abbreviations}

ACR: American college of radiology; ADC: Apparent diffusion coefficient; BIRADS: Breast imaging reporting and data system; CC: Cranio-caudal; CESM: Contrast-enhanced spectral mammography; DCE-MRI: Dynamic contrast-enhanced magnetic resonance imaging; DCIS: Ductal carcinoma in situ; DWI: Diffusion-weighted imaging; IDC: Invasive ductal carcinoma; ILC: Invasive lobular carcinoma; MLO: Mediolateral oblique; NPV: Negative predictive value; PPV: Positive predictive value; ROC: Receiver operating characteristic; ROI: Region of interest; SD: Standard deviation 


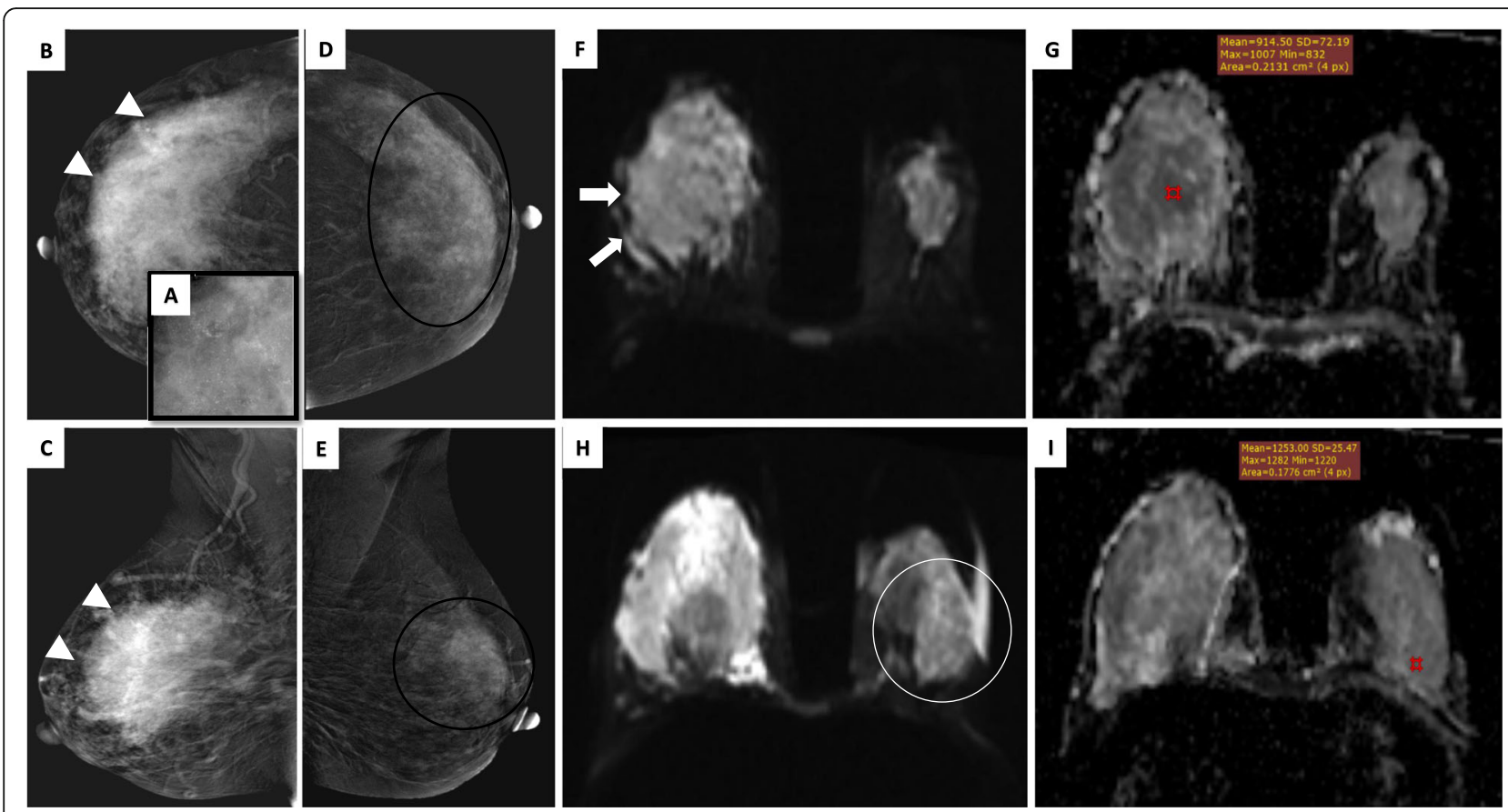

Fig. 8 A 37-year-old female patient presented with left breast lump. $\mathbf{a}$ and $\mathbf{b}$ CESM CC and MLO views of the left breast show no contrast-enhanced masses. $\mathbf{c}$ and $\mathbf{d} \mathrm{DW}$ and ADC cuts of the left breast show UIQ (white circle) well-defined oval-shaped mass eliciting restricted diffusion with corresponding mean ADC value of $1.2 \times 10^{-3} \mathrm{~s} / \mathrm{mm}^{2}$ (BIRADS 4). Tru-cut biopsy of the left breast revealed UIQ fibroadenoma

Table 8 Agreement between CESM and MRI as regards lesion classification as probably malignant (BIRADS 4-5) or probably benign (BIRADS 1-3)

\section{Lesion classification by DW MRI}

Probably benign (BIRADS 1-3)

Probably malignant (BIRADS 4-5)

Total

Lesion classification by CESM

Probably benign (BIRADS 1-3)

Probably malignant (BIRADS 4-5)

1

$2.5 \%$

5

$12.5 \%$




\section{Acknowledgements}

This research was carried out at Baheya Charity Women's Cancer Hospital and Generalized Air Forces Hospital which are fully equipped by modern machines for breast cancer diagnosis. We want to thank our colleagues who helped us to do such research work.

\section{Authors' contributions}

$\mathrm{RF}$ wrote the manuscript and was responsible for correspondence to journal. SM collected patient data and participated in its design. AA and MF did image processing and collection of patient's images. WA participated in the design of the study and performed the statistical analysis. HE conceived of the study and participated in its design and coordination and helped to draft the manuscript. The authors have read and approved the manuscript.

\section{Funding}

No funding sources

\section{Availability of data and materials}

The datasets used and analyzed during the current study are available from the corresponding author on reasonable request.

\section{Ethics approval and consent to participate}

The study was approved by the ethical committee of "Research Ethics Committee at the Faculty of Medicine, Ain Shams University" with ethical committee approval number FMASU M D 193/2018 and approval date 22/ 07/2018. An informed written consent was taken from all subjects.

\section{Consent for publication}

All patients included in this research gave written informed consent to publish the data contained within this study.

\section{Competing interests}

No financial or non-financial competing interests.

\section{Author details}

'Department of Diagnostic Radiology, Dar Elsalam Cancer Center, Ministry of Health, Cairo, Egypt. ${ }^{2}$ Egyptian Military Medical Academy, Cairo, Egypt.

${ }^{3}$ Department of Diagnostic and Interventional Radiology, Ain Shams

University, Cairo, Egypt.

Received: 3 December 2020 Accepted: 10 February 2021

Published online: 22 February 2021

\section{References}

1. Kuhl CK, Strobel K, Bieling H, Leutner C, Schild HH, Schrading S (2017) Supplemental breast MR imaging screening of women with average risk of breast cancer. Radiology 283(2):361-370

2. Sogani J, Morris EA, Kaplan JB, D'Alessio D, Goldman D, Moskowitz CS, Jochleson MS (2017) Comparison of background parenchymal enhancement at contrast-enhanced spectral mammography and breast MR imaging. Radiology 282(1):63-73

3. Yousef AF, Khater HM, Jameel LM (2018) Contrast-enhanced spectral mammography versus magnetic resonance imaging in the assessment of breast masses. Benha Med J 35:5-12

4. Partridge SC, McDonald ES (2013) Diffusion weighted magnetic resonance imaging of the breast protocol optimization, interpretation, and clinical applications. Magn Reson Imaging Clin N Am 21(3):601-624

5. Amornsiripanitch N, Bickelhaupt S, Shin HJ, Dang M, Rahbar H, Pinker K, Partridge S (2019) C: Diffusion-weighted MRI for unenhanced breast cancer screening. Radiology 9:1-17

6. Jochelson MS, Dershaw DD, Sung JS, Heerdt AS, Thornton C, Moskowitz CS, Ferrara J, Morris EA (2013) Bilateral contrast-enhanced dual-energy digital mammography: feasibility and comparison with conventional digital mammography and MR imaging in women with known breast carcinoma. Radiology 266:743-751

7. Luczyńska E, Heinze-Paluchowska S, Dyczek S, Blecharz P, Rys J, Reinfuss M (2014) Contrast-enhanced spectral mammography: comparison with conventional mammography and histopathology in 152 women. Korean J Radiol 15(6):689-696
8. Schnall MD, Blume J, Bluemke DA, DeAngelis GA, DeBruhl N, Harms S, Gatsonis CA (2006) Diagnostic architectural and dynamic features at breast MR imaging: multicenter study. Radiology 238(1):42-53

9. Muller S, Dromain C, Balleyguier C, Patoureaux F, Puong S, Bouchevreau X, Katz C (2010) Contrast enhanced digital mammography (CEDM): from morphological to functional mammography. European society of Radiology ESR/ECR 2010 / C-0300: ECR.

10. Fallenberg EM, Dromain C, Diekmann F, Engelken F, Krohn M, Singh JM, Ingold-Heppner B, Winzer K, Bick U, Renz DM (2013) Contrast-enhanced spectral mammography versus MRI: initial results in the detection of breast cancer and assessment of tumour size. Eur Radiol 24(1):256-264

11. Helal MH, Mansour SM, Ahmed HA, Abdel Ghany AF, Kamel OF, Elkholy NG (2019) The role of contrast-enhanced spectral mammography in the evaluation of the postoperative breast cancer. Clinical Radiology. 74:771-781

12. Woodhams R, Ramadan S, Stanwell P, Sakamoto S, Hata H, Ozaki M, Kan S, Inoue Y (2011) Diffusion-weighted imaging of the breast: principles and clinical applications. RSNA RadioGraphics 31:1060-1082

13. Moukhtar FZ, Abu El Maati AA (2014) Apparent diffusion coefficient values as an adjunct to dynamic contrast enhanced MRI for discriminating benign and malignant breast lesions presenting as mass and non-mass like enhancement. Egypt J Radiol Nucl Med 45:597-604

14. Pereira FPA, Martins G, de Oliveira RDVC (2011) Diffusion magnetic resonance imaging of the breast. Magn Reson Imaging Clin N Am 19(1):95-110

15. Barra FR, Sobrinho AB, Barra RR, Magalhaes MT, Aguiar LR, Lins De Albuqurque GF, Costa RP, Farage L, Pratesi R (2018) Contrast-enhanced mammography (CEM) for detecting residual disease after neoadjuvant chemotherapy: a comparison with breast magnetic resonance imaging (MRI). BioMed Res Int 2018:1-9

\section{Publisher's Note}

Springer Nature remains neutral with regard to jurisdictional claims in published maps and institutional affiliations.

\section{Submit your manuscript to a SpringerOpen ${ }^{\circ}$ journal and benefit from:}

- Convenient online submission

- Rigorous peer review

- Open access: articles freely available online

High visibility within the field

- Retaining the copyright to your article

Submit your next manuscript at $\boldsymbol{\nabla}$ springeropen.com 